\title{
KNOWLEDGE OF MEDICAL LAW AMONGST DOCTORS OF INTERNAL DISEASES
}

\author{
JUSTYNA ZAJDEL ${ }^{1}$, RADOSŁAW ZAJDEL ${ }^{2}$, and PIOTR KUNA ${ }^{3}$ \\ ${ }^{1}$ Medical University of Lodz, Łódź, Poland \\ Department of Medical Law, Chair of Humanities \\ ${ }^{2}$ Medical University of Lodz, Łódź, Poland \\ Department of Medical Informatics and Statistics \\ ${ }^{3}$ Medical University of Lodz, Łódź, Poland \\ 2nd Chair of Internal Diseases, Department of Internal Diseases, Asthma and Allergy
}

\begin{abstract}
Objectives: In Poland, 95\% of medical personnel had not received legal education before they completed their studies. Having been given these facts, we have started questioning legal awareness of people providing medical services. Aim of the study: The study aimed at evaluating the knowledge of allergists and pulmonologists. Material and Methods: The group consisting of 328 allergists and/or pulmonologist completed the questionnaire. Results: The participants possess the best knowledge in providing information to patients about their health status (CV1). Sixty nine \% of responders replied correctly, and the difference was significant $(\mathrm{p}<0.001)$ in comparison with next aspect referring to the principles of providing medical services following guidelines created by think-tanks and also possibilities to take autonomous decisions by physicians (CV2). The correct answers in relation to CV2 were given by $57 \%$ of responders. The third compared aspect was physicians' awareness of patients' right to giving a consent or refusal before undertaking the medical procedure CV3. Only 55\% of physicians gave correct answers and the difference was significant compared to CV1 ( $p<0.001)$ as well as CV2 $(\mathrm{p}<0.05)$. Younger doctors showed to have better knowledge than their older colleagues $(\mathrm{p}<0.05)$. Working in urban workplaces proved to be more associated with better knowledge than in rural ones $(\mathrm{p}<0.05)$. Discussion: Insufficient knowledge results in a low quality of provided services and puts the doctors at risk of being liable. The rates indicate that doctors are not aware of the fact that only legal regulations are binding, while standards not published by the Minister of Health are not legally valid. Half of the respondents have the wrong belief that the opinions expressed by experts make the doctor feel exempt from liability. Probably there are specialities, like occupational medicine which are specially linked with awareness of valid legal rules.
\end{abstract}

Key words

Medical law, Informed consent, Legal awareness, Patients' rights

\section{INTRODUCTION}

The knowledge of legal regulations is invaluable in order to perform medical work properly. Especially medical doctors should possess possibly most profound legal knowledge. Their knowledge is directly connected with a scope of competences which a doctor should have while providing medical services and also involves the risk of violating the patients' rights and occurrence of negative medical incidences. It should be pointed out that one should make every effort to get familiar with law and learn formal and procedural regulations to avoid misinterpretation of legal provisions in order to improve the quality of the provided

Received: April 24, 2012. Accepted: September 24, 2012.

Justyna Zajdel and Radosław Zajdel contributed equally to this work.

Corresponding author: J. Zajdel, Department of Medical Law, Chair of Humanities, Medical University of Lodz, ul. Lindleya 6, 90-131 Łódź, Poland (e-mail: justyna.zajdel@umed.lodz.pl). 
services. In the Polish law, there are around 200 normative acts which directly or indirectly refer to patients' rights. The most important is "The Act on Patient's Right and Patient's Right Spokesman" of 6 November 2008 [1]. In many aspects, the Act contains elements of "The Act on the Medical Doctor Profession and the Dentist Profession" of 5 December 1996 [2]. Thus, we can conclude that each of a patient's rights is connected with the doctor's duty to abide by the particular law and provide medical services. The procedure a doctor carries out while providing medical services remains in a close relationship with current legal regulations. Thus, we will emphasize that he/she should be educated and competent in the field of law. About $95 \%$ of medical personnel had not been provided with legal education before they completed their studies. Besides, there are not any standard programmes for educating medical personnel in the field of legal regulations. Having been given these facts, we have started questioning legal awareness of people providing medical services. In professional literature, only few articles present this problem.

Article 18, Point 1 of "The Act on the Medical Doctor Profession and the Dentist Profession" clearly states that a doctor is obliged to improve his competences in the field of legal regulations [2]. Doing one's best for the sake of successful diagnostic and therapeutic process includes application of the optimal procedures which remain in compliance with current medical knowledge, and elimination of behaviour which would violate the patient's rights in the whole treatment procedure.

In the work we tried to evaluate the knowledge of allergists and pulmonologists and see whether they respects patients' rights while they provide medical help.

\section{THE AIM OF THE STUDY}

The study aimed at evaluating the knowledge of allergists and pulmonologists. We tried to find out whether doctors are knowledgeable enough in medical law to be able to:
1. Inform the patient on the procedure of the medical services to be provided.

2. Respond to patient's consent or refusal to be treated.

3. Behave in compliance with treatment standards.

Moreover, we also attempted to find a relationship between the knowledge on the points enlisted above and selected demographic factors - the age of the doctor, his/her work experience and workplace.

In result, we aim to provide the reference background for future comparisons between doctors of varying specialities. On the other hand, the discriminative comparison will allow us to find the weakest points in medical law awareness and develop and implement supplementary curricula for medical students or professionals.

\section{MATERIAL AND METHODS}

Questionnaire sheets were circulated in a group of allergists and pulmonologists. The sheets were randomly distributed amongst 700 participants of 10th International Congress of Polish Society of Allergology held in October, 2009 in Bydgoszcz, Poland, who declared to be allergists or/and pulmonologists. The survey was completely anonymous. No personal data were recorded or collected. The completion of the questionnaire sheet had not been supervised. All the participant who received the questionnaire sheet were asked to return it to the Congress Office before their departure. Four hundred forty five forms were collected $(63.57 \%)$; however, only $328(46.86 \%)$ doctors who returned properly filled-in questionnaire sheets were selected as the participants of the study. The proper completion of survey questionnaire represented filling of all form fields, i.e. answering all questions. Due to the limited period of availability of doctors during the Congress, no computer or web assisted methods were involved. The survey consisted of 30 questions on medical law and four preceding questions on demographic variables. Demographic data collected 
in the survey comprised age, work experience, type of employment (contract of employment or commissioned work) and workplace (industrial area or rural area). No participant gender information was recorded. We recognised gender not be interesting discriminating variable to us due to the aim of investigation. We deliberately omitted determining the gender of the respondents, having regard to the intermediate target of the study, which was studying their tendency to comply with the law in the general population. We intended to evaluate the general and specific medical law knowledge needed to behave in compliance with legal requirements in the subpopulation of Polish allergists and pulmonologists. We wanted to focus on the subgroup of "well qualified" doctors and capture the tendency to obey the rules. However, we had not managed to find any discriminative features allowing such a subtraction. In this situation, knowing the Polish statutory obligation of continuous education of physicians, we assumed the participation in international congress as a feature indicating the doctor's tendency to act in accordance with the law.

The studied group consisted of 328 subjects. However the gender of the respondents was considered an unimportant criterion which did not make the population different, we divided the study group according to the age: 1) up to 35 years of age, 2) 36-45 years of age and 3) above the age of 45.

For purposes of statistical analysis, we have constructed a tool named "complex variable" (CV). The structure of this tool consisted of basic variable values including encoded responses to particular questions of the questionnaire module. As the questions related to a given module concerned the same aspect of medical law, we recognized that we could use a tool called "complex variable" in the process of data analysis. For purposes of this paper, a "complex variable", grouping answers to questions from the first module was called the term "first variable complex". According to this concept, the second module answers were grouped in "complex variable" called "second complex variable" (CV2), and third modules' - the "third complex variable" (CV3). The idea of constructing the "complex variables" or "multiparameter factors" is a recognised tool of statistical analysis of survey studies and can be used when the elementary questions concern the same problem [3]. In the sense of mathematical background, the complex variable allows for comparing the results as for each of the variables a possible value interval is from 0 to 1 , where " 0 " means that the doctor has not given correct answers to the extra questions. "1" means that the doctor has given only correct answers. The variables were thus standardized.

The survey was anonymous. The questionnaire was divided in three modules preceded by four demographic questions. The first module included questions about physicians' obligations and patients' rights in providing information to patients about their health status. The first module was called "medical information" and comprised questions 1-10. For statistical purposes, it was represented by CV1.

The second module, referred to a consent or refusal to be provided with medical help (called "a consent or refusal") and included the way and form of expressing a consent or refusal as well as particular cases of taking decisions with regard to planned medical treatment procedures. For statistical purposes, it was represented by CV2. The second module comprised questions 11-21.

The third module, called "standards", referred to the principles of providing medical services following guidelines created by think-tanks and also possibilities to take autonomous decisions, which is a characteristic feature of the medical profession. For statistical purposes, it was represented by $\mathrm{CV} 3$. The third module comprised questions 22-30.

By making up around 8-12 additional questions to each studied aspect, the researchers were able to evaluate the doctors' factual knowledge. 
In order to evaluate general legal awareness, the subjects of the survey were asked whether patients have recently become more claiming. More demanding patients require from the doctor an increased necessity to be legally competent and thus, more legally aware.

The survey volunteers were allowed to answer "Yes", "No" or "I don't know". Below we present the survey.

\section{Demographic data}

1. Age.

2. Work experience.

3. Employment: contract of employment, commissioned work.

4. Workplace: industrial area, rural area.

\section{Module 1: Questions}

\section{on medical information}

1.1. Do you think that the patient during the treatment process should be informed by the doctor on a negative prognosis?

1.2. Should the diagnosis and other information entered in the patient's hospital chart be written in Polish?

1.3. Does understanding and processing of the information given by the doctor depend on the patient's education level, his/her age and living place?

1.4. Should the doctor provide the patient with information in the most possible informative way?

1.5. Do you think that the doctor is obliged to give the patient information on potential but not frequently appearing complications of higher-risk diagnostic procedures?

1.6. Do you think that the doctor should be obliged to give information on alternative methods of treatment, including alternative pharmacological methods?

1.7. Do you think that the doctor should inform the patient on a possibility to buy needed medical equipment, medicaments etc. on his/her own if the medicaments, equipment etc. financed with the state health care are not sufficient to continue the treatment process?

1.8. Do you think that the doctor has a right (without patient's consent) to notify the closest people that the patient is a HIV virus carrier or is AIDS sick?

1.9. Do you think that the doctor should inform the patient who has been admitted to hospital that his biological material will be used to check HIV virus/ AIDS presence?

1.10. Do you think that the doctor should inform the patient's closest relatives (the spouse, children, parents) on the treatment process if such relatives are actually not most confident people?

\section{Module 2: Questions referring to a consent or refusal to be provided with medical help}

2.1. Do you think that the doctor should express his consent to be provided with higher-risk diagnostic procedures in a written form?

2.2. Do you think that allergy tests are higher-risk diagnostic procedures?

2.3. Do you think that bronchoscopy is a higher-risk procedure?

2.4. Do you think that the consent to perform a higherrisk procedure should be written by the patient himself/herself?

2.5. Do you think that the doctor should be obliged to ask for a consent to perform a higher-risk medical treatment or diagnostic procedure from the closest relatives of the patient if he/she is unconscious?

2.6. Do you think that the doctor should be obliged to ask for a consent to perform a higher-risk medical treatment or diagnostic procedure from the closest relatives of the patient if he/she: is elderly, logical contact with him/her is not possible or limited?

2.7. Do you think that a consent to an invasive medical procedure expressed by an alcohol-intoxicated patient is valid? 
2.8. Do you think that the doctor should have a right to change or extend the medical procedure which he has already started without another consent given by the patient?

2.9. Do you think that the doctor should have a right to ask the patient to give a consent to a potential extension of the scope of medical procedures?

2.10. Do you think that the doctor should have a right to perform blood transfusion in a person who remained conscious and orally expressed his/her refusal for such transfusion?

2.11. Do you think that the patient who is discharged from hospital at his own request should confirm such discharge in the hospital medical documents?

\section{Module 3: Questions on prophylaxis and treatment methods}

3.1. Do you think that providing medical services in compliance with regulations created by think-tanks protects the doctor against taking on responsibility for his/her patients?

3.2. Do you think that the regulations concerning the doctor's behaviour should be created by the Minister of Health and published in the Journal of Laws?

3.3. Do you think that the doctor who is a freelance employee has a right to reject certain guidelines described in regulations on the proper behaviour, and apply treatment procedures which in the doctor's opinion are better or more effective?

3.4. Do you think that the doctor should be subject to civil, criminal or professional liability if he/she has rejected standard guidelines on prophylaxis and treatment?

3.5. Do you think that contracting medical services by the National Health Fund facilitates practical application of prophylaxis and treatment created by think-tanks?

3.6. Do you think that medical products which are sponsored from public money allow for application of the best and most effective method in the majority of clinical cases?

3.7. Do you think that the way of contracting medical services by the National Health Fund allows the doctor to take autonomous decisions on the treatment procedures?

3.8. Do you think that the doctor should be obliged to inform the patient on the possibility to pay for the most effective method of treatment, not available for public money?

3.9. Do you think that patients have recently become more demanding?

Based on the results of the survey, the researchers analyzed the relationship between the knowledge of doctors and their hypothetical responsibility for violating the patient's rights while providing medical services. We suggested adopting so called "educational model", which aims at improving the quality of medical services and thus reducing the physicians' exposure to taking responsibility. To determine the statistically significant difference between the three studied groups of questions (modules), a comprehensive analysis was performed (Friedman's Anova and Kendal coefficient of concordance). Next, with Wilcoxon matched pairs test, the researchers attempted to find a significant difference between the created complex variables (CV1, CV2, CV3).

Next, selected demographical factors were taken into consideration. They were treated as variables and included in the analysis when the researchers tried to find a correlation between the factors and answers to the questions on medical law. The studied variables included: age, work experience, employment and workplace. The variable "form of employment" might have comprised two things: contract of employment and commissioned work. The variable "workplace" might have comprised: urban area and rural area.

The variable "work experience" included a period of time in which the person worked in a medical profession, no 
matter whether or not he/she was a medical specialist. The variable "work experience" included four groups. The criteria for looking for significant differences were four different periods of professional experience: up to 10 years, $10-20$ years, 20-30 years and above 30 years. The variable "workplace" initially comprised three aspects: industrial, urban and rural areas. To make the results more clear, the authors combined the variable "industrial area" with the variable "urban area" and changed them into one variable - "city area".

The researchers took a decision to make a synthesis of the detailed information in the studied material (empirical) so as to find some regularities in the studied population. In order to describe the studied group, indices of structures were calculated in the analysis of qualitative character. To determine a mean value for the qualitative characters, the authors calculated the arithmetic mean $(\bar{x})$ and median (Me). Standard deviation (SD) constituted a dispersion value. The range of the studied variables, i.e. minimum and maximum values, was also determined. To obtain a better distribution, the authors determined also the coefficient of skewness.

The answers which the doctor ticked "I do not know" were considered incorrect, too. The authors decided that only this medical professional who has a comprehensive knowledge of current legal regulations will take on responsibility and the risk of making a mistake will be lower.

The researchers applied a comprehensive statistical analysis for independent variables, i.e. Anova non-parametric test, Kruskal-Wallis rank test (because the distribution of the studied characters did not correspond to the normal distribution), Shapiro-Wilk test (because of the structure and the scale of the studied parameters), which is a corresponding test for a variance analysis and matches statistical requirements for that kind of analysis (the studied variables) as well as for two independent variables - U MannWhitney test [4]. A comprehensive statistical analysis, i.e. Friedman's ANOVA non-parametric test was applied for dependent variables and Wilcoxon test - between the two variables [4]. STATISTICA 8.0. software was used for calculation purposes.

\section{RESULTS}

Three hundred and twenty-eight doctors, both males and females, took part in the study. The distribution of the studied group in terms of age and work experience was not normal. The age median was 46 years, mean -45.4 years, standard deviation -10.3 years. The work experience median was 19.5 years, mean - 19.2 years, standard deviation -10.1 years.

\section{A comprehensive statistical analysis of the results of the answers to additional questions influencing CV1, CV2, CV3}

The results obtained in the general, i.e. demographicvariables-independent analysis of the answers to the survey questions confirm that the studied doctors possess the best knowledge of the additional questions, constituting the CV1, that is "medical information". Sixty nine peer cent of the answers were correct. Only $55 \%$ of the studied volunteers, i.e. the smallest number, correctly answered the questions concerning a consent or refusal to be provided with medical help. With regard to the CV3, 57\% of the doctors' population correctly answered the questions. Table 1 presents the results.

The authors performed a comprehensive analysis of the complex variables to evaluate the significance of differences. It was confirmed that all the analyzed differences were statistically significant. Table 1 presents the analyzed results.

\section{A comprehensive analysis of the complex variables according to the age of the doctors}

It was confirmed there was no significant difference between the age and the knowledge of the doctors with regard to medical information (CV1). No significant 
Table 1. Analysis of physicians' answers to particular sets of questions

\begin{tabular}{|c|c|c|c|}
\hline \multirow[t]{2}{*}{ Statistical parameters } & \multicolumn{3}{|c|}{$\begin{array}{l}\text { Knowledge } \\
(\mathrm{N}=328)\end{array}$} \\
\hline & medical information CV1 & consent CV2 & standards CV3 \\
\hline Minimum & 0.11 & 0.00 & 0.00 \\
\hline Maximum & 1.00 & 0.91 & 1.00 \\
\hline Median & 0.67 & 0.55 & 0.57 \\
\hline Arithmetic mean & 0.69 & 0.55 & 0.57 \\
\hline Standard deviation & 0.14 & 0.14 & 0.17 \\
\hline Coefficient of skewness & -0.74 & -0.10 & -0.31 \\
\hline Statistical analysis & \multicolumn{3}{|c|}{ 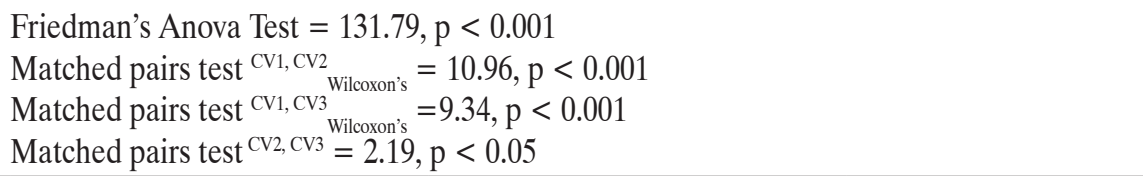 } \\
\hline
\end{tabular}

difference between the age and the knowledge of the doctors with regard to a consent or refusal to be provided with medical services was observed, either (CV2). There is, however, a statistically significant difference between the age and the knowledge of the doctors with regard to the third variable - "modern medical standards" (CV3) $(p<0.01)$. The authors proved that the knowledge of the doctors above the age of 45 rather than those below the age of 35 , is significantly less comprehensive. With regard to the 36-45 age group, the differences were not statistically significant. Table 2 presents the detailed results.

\section{A comprehensive analysis of the complex variables according to the work experience of the doctors} It was confirmed there was no significant difference between the work experience and the knowledge of the doctors with regard to medical information (CV1) ( $p>0.05)$. It should be pointed out that the knowledge of the doctors is not satisfactory - only $67-69 \%$ of the doctors gave a correct answer.

The analysis of the relationship between the second complex variable and the work experience indicates that the doctors' knowledge of a consent or refusal to be provided

Table 2. A comprehensive analysis of CV3 (standards) according to the age of the doctors

\begin{tabular}{|c|c|c|c|c|}
\hline \multirow[b]{2}{*}{ Prophylaxis } & \multicolumn{3}{|c|}{ CV3 according to the age (years) } & \multirow{2}{*}{$\begin{array}{c}\text { Total } \\
(\mathrm{N}=328)\end{array}$} \\
\hline & $\begin{array}{c}<35 \\
(\text { Group } 1, \mathrm{~N}=74)\end{array}$ & $\begin{array}{c}36-45 \\
\text { (Group 2, } \mathrm{N}=87 \text { ) }\end{array}$ & $\begin{array}{c}>45 \\
(\text { Group 3, N }=167)\end{array}$ & \\
\hline Minimum & 0.00 & 0.14 & 0.00 & 0.00 \\
\hline Maximum & 1.00 & 1.00 & 0.86 & 1.00 \\
\hline Median & 0.57 & 0.57 & 0.57 & 0.57 \\
\hline Arithmetic mean & 0.61 & 0.57 & 0.55 & 0.57 \\
\hline Standard deviation & 0.18 & 0.17 & 0.16 & 0.17 \\
\hline Coefficient of skewness & -0.61 & -0.15 & -0.35 & -0.31 \\
\hline Statistical analysis & \multicolumn{4}{|c|}{$\begin{array}{l}\text { Anova Test Kruskal-Wallis rank test }=7.23, \mathrm{p}<0.05 \\
\text { Test } \mathrm{Z}^{1,2}{ }_{\text {Mann-Whitney }}=1.43, \mathrm{p}>005 ; \text { Test } \mathrm{Z}^{1,3}{ }_{\text {Mann-Whitney }}=2.53, \mathrm{p}<0.01 \\
\text { Test } \mathrm{Z}^{2,3}{ }_{\text {Mann-Whitney }}=1.02, \mathrm{p}>0.05\end{array}$} \\
\hline
\end{tabular}


Table 3. An analysis of CV2 (a consent or refusal to be provided with medical services) according to the work experience of the doctors

\begin{tabular}{|c|c|c|c|c|}
\hline \multirow[b]{2}{*}{ Treatment procedure } & \multicolumn{4}{|c|}{ CV2 according to the work experience (year) } \\
\hline & $\begin{array}{c}<10 \\
(\text { Group } 1, \mathrm{~N}=75)\end{array}$ & $\begin{array}{c}10-20 \text { years } \\
\text { (Group } 2, \mathrm{~N}=89 \text { ) }\end{array}$ & $\begin{array}{c}20-30 \\
(\text { Group } 3, \mathrm{~N}=95 \text { ) }\end{array}$ & $\begin{array}{c}>30 \\
(\text { Group 4, N }=69)\end{array}$ \\
\hline Minimum & 0.09 & 0.18 & 0.27 & 0.00 \\
\hline Maximum & 0.91 & 0.82 & 0.82 & 0.91 \\
\hline Median & 0.55 & 0.55 & 0.55 & 0.45 \\
\hline Arithmetic mean & 0.56 & 0.56 & 0.54 & 0.51 \\
\hline Standard deviation & 0.15 & 0.14 & 0.13 & 0.15 \\
\hline Coefficient of skewness & 0.03 & -0.11 & 0.26 & -0.56 \\
\hline Statistical analysis & \multicolumn{4}{|c|}{ 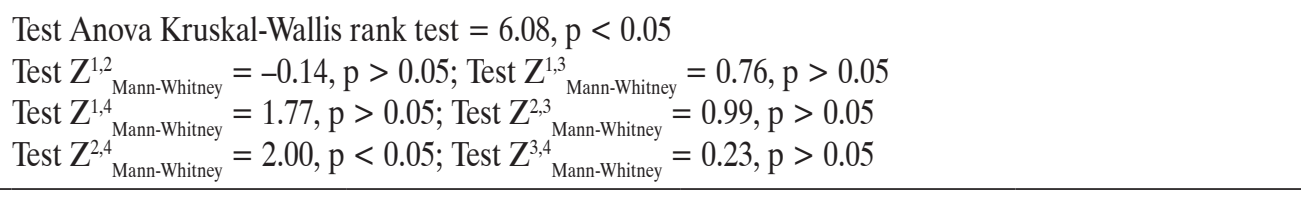 } \\
\hline
\end{tabular}

with medical services becomes less profound when they gain work experience. However, only Group 2 (with work experience: 10-20 years) gave significantly better answers than the doctors having the longest work experience. Thus, it can be concluded that the doctors with short work experience demonstrate a relatively comprehensive knowledge. It should be emphasized that a little more than half the doctors gave here correct answers. Table 3 presents the detailed results.
Similarly to the previous analysis, the doctors' knowledge of providing medical services in compliance with certain guidelines set forth by think-tanks as well as the possibility to take autonomous decisions, which is a characteristic feature of freelance professionals, becomes less profound when the doctors gain work experience. The dependence is statistically significant with comparison to the doctors who have the shortest and longest work experience. Table 4 presents the detailed results.

Table 4. An analysis of CV3 (standards) according to the work experience of the doctors

\begin{tabular}{|c|c|c|c|c|}
\hline \multirow[b]{2}{*}{ Prophylaxis } & \multicolumn{4}{|c|}{ CV3 according to the work experience (year) } \\
\hline & $\begin{array}{c}<10 \\
(\text { Group } 1, \mathrm{~N}=75)\end{array}$ & $\begin{array}{c}10-20 \text { years } \\
\text { (Group 2, } \mathrm{N}=89 \text { ) }\end{array}$ & $\begin{array}{c}20-30 \\
(\text { Group } 3, \mathrm{~N}=95)\end{array}$ & $\begin{array}{c}>30 \\
(\text { Group } 4, \mathrm{~N}=69)\end{array}$ \\
\hline Minimum & 0.00 & 0.14 & 0.29 & 0.00 \\
\hline Maximum & 1.00 & 1.00 & 0.86 & 0.86 \\
\hline Median & 0.57 & 0.57 & 0.57 & 0.00 \\
\hline Arithmetic mean & 0.61 & 0.57 & 0.55 & 0.55 \\
\hline Standard deviation & 0.18 & 0.17 & 0.14 & 0.18 \\
\hline Coefficient of skewness & -0.61 & -0.11 & -0.06 & -0.57 \\
\hline Statistical analysis & \multicolumn{4}{|c|}{ 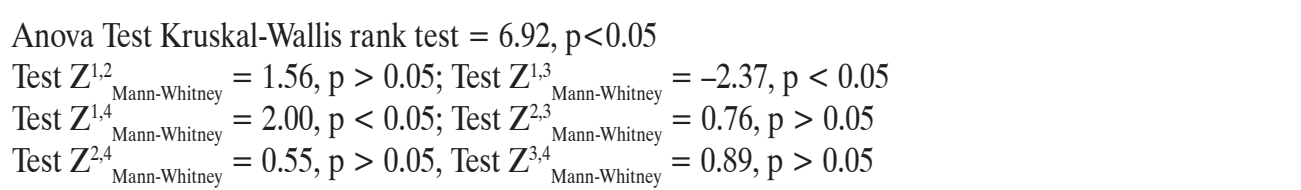 } \\
\hline
\end{tabular}




\section{A comprehensive analysis of the complex variables according to the workplace of the doctors}

Another step in the study was the analysis of the complex variables according to the workplace. It was confirmed that the doctors working outside city limits, defined as rural areas, demonstrated a less comprehensive knowledge of the studied issues of medical law. It should be pointed out, however, that the difference was statistically significant only with regard to the CV1, i.e. medical information $(\mathrm{p}<0.05)$. With regard to the remaining complex variables, the differences were statistically significant $(p>0.05)$. Table 5 presents the detailed results.

\section{A comprehensive analysis of the complex variables} according to the employment of the doctors

No statistically significant relationship was noted between the knowledge of the doctors with regard to any complex variable and the way they were employed $(\mathrm{p}<0.05)$.

In Table 6 the authors selected those questions which appeared to be particularly difficult for some doctors and the number of incorrect answers indicated relative ignorance in legal issues. The researchers included also the questions to which the doctors gave correct answers. Nevertheless, they were so important questions that the percentage of correct answers was still considered unsatisfactory.

Table 5. An analysis of CV1 (medical information) according to the workplace

\begin{tabular}{lccc}
\hline \multirow{2}{*}{ Medical information } & \multicolumn{2}{c}{$\begin{array}{c}\text { CV1 according to the } \\
\text { workplace }\end{array}$} & \begin{tabular}{c} 
Total \\
\cline { 2 - 3 }
\end{tabular} \\
\cline { 2 - 3 } & $\begin{array}{c}\text { urban areas } \\
(\mathrm{N}=263)\end{array}$ & $\begin{array}{r}\text { rural areas } \\
(\mathrm{N}=65)\end{array}$ & \\
\hline Minimum & 0.22 & 0.11 & 0.11 \\
Maximum & 1.00 & 1.00 & 1.00 \\
Median & 0.67 & 0.67 & 0.67 \\
Arithmetic mean & 0.69 & 0.65 & 0.69 \\
Standard deviation & 0.14 & 0.16 & 0.14 \\
Coefficient of skewness & -0.71 & -0.68 & -0.74 \\
Statistical analysis & Test $\mathrm{Z}_{\text {Mann-Whitney }}=2.01, \mathrm{p}<0.05$ \\
\hline
\end{tabular}

Table 6. Relative measure of the answers particularly difficult for the studied doctors

\begin{tabular}{lcc}
\hline \multirow{2}{*}{ No. of question } & \multicolumn{2}{c}{ Answer (\%) } \\
\cline { 2 - 3 } & correct & incorrect \\
\hline 3.8 & 79 & 21 \\
2.1 & 77 & 23 \\
1.6 & 70 & 30 \\
2.2 & 47 & 53 \\
3.1 & 46 & 54 \\
3.3 & 38 & 62 \\
1.9 & 24 & 76 \\
2.8 & 23 & 77 \\
2.6 & 20 & 80 \\
3.4 & 16 & 84 \\
\hline
\end{tabular}

Table 7. Relative measure of the answers particularly essential from the legal and medical point of view

\begin{tabular}{lcc}
\hline \multirow{2}{*}{ No. of question } & \multicolumn{2}{c}{ Answer (\%) } \\
\cline { 2 - 3 } & correct & incorrect \\
\hline 2.3 & 87 & 13 \\
1.1 & 74 & 26 \\
2.7 & 43 & 57 \\
1.8 & 39 & 61 \\
2.5 & 29 & 71 \\
\hline
\end{tabular}

The answers to the questions concerning some aspects of medical law which are highly important in medical practice. The questions and answers are presented in Table 7. It should be emphasized that the doctors' awareness with regard to the majority of the issues are highly insufficient. In the studied group of the allergists and pulmonologists, as many as $61 \%$ of the doctors gave incorrect answers by claiming that the patient has to give his/ her consent to inform his/her closest family that he/she is a HIV virus carrier. The analysis of the relationship between the studied answer and the demographic variables confirmed that the differences were not significant $(\mathrm{p}>0.05)$. 
Seventy four per cent of the doctors answered correctly to question no. 10 concerning informing the patient's closest relatives if such relatives are actually not most confident people. Although three fourths of the volunteers gave a correct answer, every fourth person might be accused of violating physician-patient privilege and thus, be at risk of being subject to civil, criminal and professional liability. Therefore, the result equal to $74 \%$ cannot be considered satisfactory. Like in the case of informing relatives on being a HIV virus carrier, also here, there is no relationship between the analyzed question and the demographic variables $(p>0.05)$.

Eighty seven per cent of the doctors correctly claimed that bronchoscopy is a higher-risk procedure. The analysis indicated that the doctors working in urban areas more often gave correct answers $(89 \%)$ in comparison to those from rural areas (78\%). The difference was statistically significant, $(\mathrm{p}>0.05)$. Table 8 presents the detailed results.

A great majority of the doctors (71\%) incorrectly answered to the question whether the doctor should ask for a consent to perform a higher-risk medical treatment or diagnostic procedure from the closest relatives of the patient if he/she is unconscious. The result clearly confirms that the doctors overestimate the role of the family in taking a decision on the diagnostic and therapeutic processes. Surprising remains the fact that such a tendency is most

Table 8. The analysis of the relationship between the awareness of the risk of bronchoscopy and the living place of the doctor

\begin{tabular}{|c|c|c|c|c|c|c|}
\hline \multirow{3}{*}{$\begin{array}{l}\text { Evaluation of } \\
\text { knowledge }\end{array}$} & \multicolumn{4}{|c|}{ Living place } & \multirow{2}{*}{\multicolumn{2}{|c|}{ Total }} \\
\hline & \multicolumn{2}{|l|}{ rural areas } & \multicolumn{2}{|c|}{ urban areas } & & \\
\hline & subjects $(\mathrm{n})$ & $\begin{array}{l}\text { structure index } \\
(\%)\end{array}$ & subjects $(\mathrm{n})$ & $\begin{array}{c}\text { structure index } \\
(\%)\end{array}$ & subjects (n) & $\begin{array}{c}\text { structure index } \\
(\%)\end{array}$ \\
\hline Incorrect answer & 14 & 21.54 & 28 & 10.65 & 42 & 12.80 \\
\hline Correct answer & 51 & 78.46 & 235 & 89.35 & 286 & 87.20 \\
\hline Total & 65 & 100.00 & 263 & 100.00 & 328 & 100.00 \\
\hline Statistical analysis & \multicolumn{6}{|c|}{ Test $\mathrm{Chi}_{\text {Pearson }}^{2}=5.54, \mathrm{p}<0.05 ;$ Test $\mathrm{Chi}_{\mathrm{NW}}^{2}=4.95, \mathrm{p}<0.05$} \\
\hline
\end{tabular}

Table 9. The analysis of the relationship between the doctors' awareness with regard to asking the unconscious patient's family for a consent to perform a higher-risk medical treatment or diagnostic procedure and their work experience

\begin{tabular}{|c|c|c|c|c|c|c|c|c|c|c|}
\hline \multirow{3}{*}{$\begin{array}{l}\text { Knowledge } \\
\text { evaluation }\end{array}$} & \multicolumn{8}{|c|}{ Work experience (year) } & \multirow{2}{*}{\multicolumn{2}{|c|}{ Total }} \\
\hline & \multicolumn{2}{|c|}{$<10$} & \multicolumn{2}{|c|}{$10-20$} & \multicolumn{2}{|c|}{$20-30$} & \multicolumn{2}{|c|}{$>30$} & & \\
\hline & $\begin{array}{l}\text { subjects } \\
\text { (n) }\end{array}$ & $\begin{array}{c}\text { structure } \\
\text { index } \\
(\%)\end{array}$ & $\begin{array}{l}\text { subjects } \\
\text { (n) }\end{array}$ & $\begin{array}{c}\text { structure } \\
\text { index } \\
(\%)\end{array}$ & $\begin{array}{l}\text { subjects } \\
\text { (n) }\end{array}$ & $\begin{array}{c}\text { structure } \\
\text { index } \\
(\%) \\
\end{array}$ & $\begin{array}{l}\text { subjects } \\
\text { (n) }\end{array}$ & $\begin{array}{c}\text { structure } \\
\text { index } \\
(\%)\end{array}$ & $\begin{array}{l}\text { subjects } \\
\text { (n) }\end{array}$ & $\begin{array}{c}\text { structure } \\
\text { index } \\
(\%) \\
\end{array}$ \\
\hline \multicolumn{11}{|l|}{ Question 15} \\
\hline $\begin{array}{l}\text { incorrect } \\
\text { answer }\end{array}$ & 51 & 68.0 & 58 & 65.2 & 66 & 69.5 & 58 & 84.1 & 233 & 71.0 \\
\hline $\begin{array}{l}\text { correct } \\
\text { answer }\end{array}$ & 24 & 32.0 & 31 & 34.8 & 29 & 30.5 & 11 & 15.9 & 95 & 29.0 \\
\hline total & 75 & 100.0 & 89 & 100.0 & 95 & 100.0 & 69 & 100.0 & 328 & 100.0 \\
\hline $\begin{array}{r}\text { Statistical } \\
\text { analysis }\end{array}$ & \multicolumn{10}{|c|}{ Test Chi $_{\text {Pearson }}^{2}=7.82, \mathrm{p}<0.05 ;$ Test $\mathrm{Chi}^{2}{ }_{\mathrm{NW}}=8.27, \mathrm{p}<0.05$} \\
\hline
\end{tabular}


often observed in the doctors who have the longest work experience. As many as $84 \%$ of the doctors with their work experience longer than 30 years think that it is the family who decide whether the unconscious patient should undergo higher risk medical procedures.

Like in the analysis of the presented relationships, also in this case, the doctors with work experience 10-20 years gave the most accurate answers. The differences were significant, $(p<0.05)$. Table 9 presents the detailed results. The issue of a refusal to undergo an invasive medical procedure expressed by an alcohol-intoxicated patient is important from a legal point of view and highly controversial. Most of the doctors included in the study could not give a correct answer. Fifty seven per cent of the doctors think that such refusal is binding. The authors did not confirm any significant relationship between the analyzed answers and the demographic variables.

\section{DISCUSSION}

In professional literature there are not many studies dealing with the analysis of doctors' knowledge of medical law. We did not find any work analyzing legal awareness of allergists and pulmonologists. Most papers presents the idea of doctors' awareness and the way of obtaining a conscious consent in the diagnostic and therapeutic process [5-9]. Some works deal with the problem of gathering all necessary information and the quality of the doctor-patient communication process [9]. Many authors claim that neither the quality of the information which is passed, nor the way in which the doctor gets a consent to carry out a higher risk diagnostic procedure $[10,11]$ or a surgery is satisfying for the doctor [12].

Conclusions drawn from other available analyses are quite similar to the conclusions made by the authors of this study. Peters states that an average rate of incorrect answers given to these 18 questions on medical law was equal to $1-75 \%$ [13]. With regard to our study, the rate of correct answers ranged from $69 \%$ for the questions concerning informing patients, to $55 \%$ for the questions concerning a consent to be medically treated. In the third module, referring to the so called standards, the percentage of correct answers was 57. In the authors' opinion, legal awareness of the doctors is insufficient. It results in a low quality of provided services and puts the doctors at risk of being liable. It should be pointed out that differences between the rates of correct answers were statistically significant $(\mathrm{p}<0.001)$.

With regard to the questions on the methods of providing medical services in compliance with certain guidelines set forth by think-tanks as well as the possibility to take autonomous decisions, which is a characteristic feature of freelance professionals, $57 \%$ of the doctors gave a correct answer. As for the CV3, the authors noted a high percentage of correct answers. That high percentage might have resulted from the fact that the researchers included the question on the awareness of the increasing demands from patients. As many as $96 \%$ of the respondents gave here a positive answer, whereas with regard to other questions, they were not so much aware and scored between $16 \%$ and $56 \%$.

The authors believe that the doctors too much rely on standards created by think-tanks and treat them as most reliable guidelines in their medical conduct. The authors claim that the doctors are not aware of the fact that only legal regulations are binding and certain standards not published by the Minister of Health are not legally valid. Less than half the respondents believe that the opinions expressed by experts make the doctor exempt from liability. Moreover, only one doctor in three knows that he has rights which are associated with a freelance profession, and such is a medical profession. The right includes the choice of such a treatment procedure, which the doctor will deem the most suitable and which he will apply in compliance with all professional knowledge and gained experience. It was confirmed that legal awareness 
with regard to the particular complex variable, was significantly lower in the group of the oldest doctors than in the younger group $(\mathrm{p}<0.01)$.

The tendency is also observed in the relationship between the variable and the work experience. The doctors with the experience longer than 20 years gave significantly more wrong answers $(p<0.05)$ than the doctors with short work experience (up to 10 years). Other demographic factors did not influence this variable. No reports on the analysis of legal awareness in such context were found. Thus, it is impossible to compare our results with those obtained by other researchers.

The comparative analysis of the CV2, defined as "the patient's consent", in relation to the first and third variables, confirms significantly poorer legal awareness of the doctors. The percentage of correct answers was 55\% and that rate is significantly poorer than the rate for the third variable $(57 \%, \mathrm{p}<0.05)$ and the first variable $(69 \%, \mathrm{p}<0.001)$. The analysis of the demographic variables confirms that only the work experience was closely related to the knowledge of this issue. The doctors who have been working longer than 30 years demonstrated significantly poorer results $(51 \%)$ than the doctors with a shorter work experience - 10-20 years (56\%, p < 0.05). It seems that we should point out that the answers to some particular questions which constituted the CV2 were highly different.

As many as $95 \%$ of correct answers were noted when the respondents were asked the question on the necessity of obtaining the patient's consent to undergo higher-risk diagnostic procedures. The results are better than those obtained by Jukic et al. [14]. They claim, only $38 \%$ of the doctors demonstrated a comprehensive knowledge on the method of obtaining a consent from patients. In our study, the percentage was much higher and $55 \%$ of the subjects gave a consent. We should stress that those good results of the general knowledge were impaired by negative answers to the questions concerning the way of reacting to unconscious patients and older ones, who do remain in a limited logical contact. Only one doctor in five knew that he did not have to ask the patient's family to give him/her consent. Three doctors in ten would not try to get a consent from the family to treat the unconscious patient. It should be pointed out that only $15 \%$ of the doctors with the work experience longer than 30 years gave a positive answer.

The doctors with shorter work experience gave much better answers from the statistical point of view (more than $30 \%$ of the correct answers in the remaining groups, $\mathrm{p}<0.05)$. Eighty seven per cent of the doctors are aware of the fact that they should ask the patient to express his/ her consent before the decision on extending surgical procedures and $91 \%$ demand the patient confirm his/her decision to leave hospital if such decision was taken by the patient only. The analysis in which we compare the results with some other professional literature seems interesting. Chadha states that almost $31 \%$ of the doctors and $62 \%$ of other medical personnel are not right to believe that the patient's close relative should take a decision about giving a consent if the patient is not able to give it by himself/ herself. British doctors appear to be more knowledgeable than Polish doctors ( $71 \%$ of incorrect answers) in this respect [15]. The decision against blood transfusion might be treated as an objection not against treatment but against saving life. Seventy seven per cent of the asked respondents answered the question correctly. The result is similar to the result of Evans et al., who observed that $90 \%$ of the doctors working in the medical emergency department treat the patients illegally if they do not agree to such treatment [16]. Similarly, 90\% of Evans's subjects gave the same answer and stated that the patient's family does not to have to give a consent or refusal if such cannot be obtained from the patient. The presented example confirms certain ignorance of the Polish doctors.

The doctors who participated in the study demonstrated the best knowledge with regard to the variable concerning 
the questions on informing patients. The rate of correct answers is slightly better than in other authors. Chate shows that the average percentage of correct answers in the study on dentists was 57\% and was lower in the questions on the information given to patients and the ways of verification how the information was understood [6].

The author tries to emphasize a poorer result in the case of patients unable to express their autonomous decisions. The mentioned results corresponds to the results obtained by the authors of the study, in which less than half the respondents is knowledgeable in this respect. There are inclinations to get a patient to make a conscious choice [7] rather than express a conscious consent. In the light of the above tendency, we should point out that the rate of correct answers to the question concerning alternative methods of treatment is relatively high. In our study $70 \%$ of the doctors gave a correct answer.

The result might imply that the doctors properly treat the patients' decisions and respect their autonomy [17]. The conducted analysis did not confirm any significant relationships between the CV1 - "information" and the age of the doctors and their work experience ( $p>0.05$ ). However, there was a significant difference with regard to workplace. The doctors working in urban areas gave $69 \%$ of the correct answers, whereas in the case of the doctors working in rural areas, the percentage was only $65 \%$ $(p<0.05)$. Like in the other complex variables, employment was not a factor contributing to a greater number of incorrect answers.

In our study, $89 \%$ of the doctors are right by saying that the patient should be given information on a negative prognosis. A similar high rate $(84 \%)$ of correct answers was observed in the question on the necessity of informing the patient on potential but not frequently appearing complications of higher-risk diagnostic procedures. Other authors claim that patients expect to be informed on potential complications not more rarely than in $1 / 1000$ cases (Newton-Howes [18], and Jamjoom [19]). The authors of this study, however, state that patients should be informed on "potential complications". Such an attitude should contribute to a decrease of the risk of liabilities as there are not official recommendations with regard to the behaviour in such circumstances.

The opinions of other authors refer to the medical environment of Great Britain and in our opinion cannot correspond to the Polish reality. The rate of the correct answers to the question: "Do you think that the doctor should inform the patient's closest relatives (the spouse, children, parents) on the treatment process if such relatives are actually not most confident people?" is relatively high (74\%). Yet, the authors of the article claim that the knowledge of the medical professionals is in this respect insufficient.

The reason why the doctors gave such answers is the opinion that informing the person on the patient's treatment process, when the patient does not really trust the closest relative, is considered violating the physician-patient privilege and thus, is the sufficient cause of making the doctor be subject to civil, criminal and professional liability. In the author's opinion, the role and rights of the confident person as well as the responsibilities of medical personnel should be a key topic of constant training for medical professionals in Poland. A relatively high rate of correct answers (79\%) to the question concerning the choice of the language in which the diagnosis and other information should be entered in the patient's hospital chart, can be interpreted as respect of the patient's autonomy. This result corresponds to the data obtained by other authors. Jamjoom says that $79 \%$ of the asked doctors combine informing their patients with the respect for their autonomy [19]. We should also focus our attention on the fact that the doctors do not really know much about the procedure of informing the closest family of the patient that he/she is a HIV virus carrier. Only $39 \%$ of the respondents gave a correct answer by claiming that the doctor has a right (and a duty) to inform the family without the consent of 
the patient that the patient is a HIV virus carrier. It should be pointed out that a doctor is obliged to inform the patient's closest relatives on the immediate risk of getting infected with a HIV virus or coming down with sickness or any other risky situations posing a life threat. Even smaller number of the doctors (24\%) gave a correct answer to the question concerning the necessity of informing the patient who has been admitted to hospital that his biological material would be used to check HIV virus/AIDS presence. The authors stress that present professional literature does not answer whether a doctor should inform the patient of that fact but in what way he should do it. Hogben from The Centre for Disease Control and Prevention in Atlanta claims in his study that informing partners is the most effective measure preventing sexually transmitted diseases from spreading [20]. The duty to inform the closest relatives is connected with the Polish legal regulations [2]. Polish doctors are alarmingly legally unaware in this respect. Such lack of knowledge calls for implementing intensive educational campaigns.

We hold the opinion that specialized training programmes on medical law should be introduced. Such training will contribute to an increase in the legal awareness of medical professionals, as confirmed earlier by other authors $[13,15,19]$. Both in Poland and other countries, doctors appreciate legal knowledge; however, they reveal far too low awareness of medical law issues [21]. They are also aware of the fact that patients are becoming more and more demanding. In our study, $96 \%$ of the respondents positively replied to the question. The results correspond to the ones obtained by Saltstone et al., who observed that Canadian doctors understand the necessity to gain legal competence. Their knowledge is different in different aspects of medical law and the rate of correct answers is usually 50\% [22]. Similar results were reported by Hariharan et al. They observed that $53 \%$ of experienced doctors do not have sufficient knowledge on medical law [23]. Jukic et al. point out there should be complex solutions to training. In their study on doctors from Croatia they proved that only $38 \%$ had a comprehensive knowledge of issues connected with obtaining a consent to be provided with medical services [14]. Peters, mentioned before, states that only $51 \%$ of doctors from New Zealand had ever participated in any training on the necessity to express a consent by patients [13]. Authors admit that physicians lack sufficient competences in medical law; however, the situation differs significantly among the countries [24]. Haberko et al., having performed a study in which $65 \%$ of Polish doctors gave correct answers in the survey, conclude that not only medical students should be provided with training on medical law but such educational programmes should be also organized after completing university education, in the form of postgraduate training [25].

It is important to emphasize that some authors show a kind of interdisciplinary variability of medical law knowledge amongst the doctors. Probably there are specialities, like occupational medicine, which are specially linked with awareness of valid legal rules, that could become a reference model of such education. The aim of our next study will be to estimate the real difference in medical law awareness between occupational medicine doctors and allergists.

\section{REFERENCES}

1. Act on Patient's Right and Patient's Right Spokesman date of issue 6.11.2008 r. Journal of Law 2008, no 52, poz. 417 with futher changes [in Polish].

2. Act on the Medical Doctor Profession and the Dentist Profession date of issue 5.12.1996, uniform text. Journal of Law 2011, no 277, poz. 1634 [in Polish].

3. Watała C, Różalski M, Boncler M, Kaźmier P. Research and publications in biomedical sciences (Vol 1) - Planning and conducting research. Bielsko-Biała: $\alpha$-Medica Press; 2011. p. 89 [in Polish].

4. Domański C, Iwaszkiewicz-Zasłonka A, Jaszewski R, Zasłonka J. Use of statistical methods during examinations of 
patients with ischaemic heart disease treated by surgery. Łódź: University of Łódź Publishing House; 2003 [in Polish].

5. Sharma PK, Chate RA. Level of knowledge and understanding of informed consent amongst the training grade group orthodontists in England, Wales and Northern Ireland. J Orthod 2011;38(2):90-8.

6. Chate RA. An audit of the level of knowledge and understanding of informed consent amongst consultant orthodontists in England, Wales and Northern Ireland. Br Dent J. 2008;205(12):665-73.

7. Mayberry MK, Mayberry JF. Towards better informed consent in endoscopy: A study of information and consent processes in gastroscopy and flexible sigmoidoscopy. Eur J Gastroenterol Hepatol 2001;13(12):1467-76.

8. Fisher-Jeffes L, Barton C, Finlay F. Clinicians' knowledge of informed consent. J Med Ethics 2007;33(3):181-4.

9. Vincent JL. Information in the ICU: are we being honest with our patients? The results of a European questionnaire. Intensive Care Med 1998;24(12):1251-6.

10. O'Dwyer HM, Lyon SM, Fotheringham T, Lee MJ. Informed consent for interventional radiology procedures: A survey detailing current European practice. Cardiovasc Intervent Radiol 2003;26(5):428-33.

11. Parmar VN, Mayberry JF. An audit of informed consent in gastroscopy: investigation of a hospital's informed consent procedure in endoscopy by assessing current practice. Eur J Gastroenterol Hepatol 2005;17(7):721-4.

12. Elmalik K, Wheeler RA. Consent: luck or law? Ann R Coll Surg Engl 2007;89(6):627-30.

13. Peters C. Consenting to medical treatment: legal requirements vs. medical practice. Are healthcare providers exposing themselves to potential legal action? N Z Med J 2009;122(1300):50-9.

14. Jukic M, Kvolik S, Kardum G, Kozina S, Tomic Juraga A. Knowledge and practices of obtaining informed consent for medical procedures among specialist physicians: questionnaire study in 6 Croatian hospitals. Croat Med J 2009;50(6):567-74.
15. Chadha NK, Repanos C. How much do healthcare professionals know about informed consent? A Bristol experience. Surgeon 2004;2(6):328-33, 360 .

16. Evans K, Warner J, Jackson E. How much do emergency healthcare workers know about capacity and consent? Emerg Med J 2007;24:391-3.

17. Mayberry MK, Mayberry JF. Consent with understanding: A movement towards informed decisions. Clin Med 2002;2(6):523-6.

18. Newton-Howes PA, Bedford ND, Dobbs BR, Frizelle FA. Informed consent: what do patients want to know? N Z Med J 1998;111(1073):340-2.

19. Jamjoom AAB, White S, Walton SM, Hardman JG, Moppett IK. Anaesthetists' and surgeons' attitudes towards informed consent in the UK: An observational study. BMC Med Ethics 2010,11:2.

20. Hogben M. Partner notification for sexually transmitted diseases. Clin Infect Dis 2007;44 Suppl 3:S160-74.

21. Lazarus JV, Jaruseviciene L, Liljestrand J. Lithuanian general practitioners' knowledge of confidentiality laws in adolescent sexual and reproductive healthcare: A cross-sectional study. Scand J Public Health 2008;36(3):303-9.

22. Saltstone SP, Saltstone R, Rowe BH. Knowledge of medicallegal issues. Survey of Ontario family medicine residents. Can Fam Physician 1997;43:669-73.

23. Hariharan S, Jonnalagadda R, Walrond E, Moseley H. Knowledge, attitudes and practice of healthcare ethics and law among doctors and nurses in Barbados. BMC Med Ethics 2006;7:E7.

24. Van McCrary S, Swanson JW. Physicians' legal defensiveness and knowledge of medical law: comparing Denmark and the USA. Scand J Public Health 1999;27(1):18-21.

25. Haberko J, Kopaczyńska Z, Talikowska E, Pawelczyk L, Jedrzejczak P. Awareness of basic medical law standards among doctors and patients in Poland. Przegl Lek 2008;65(5):237-40 [in Polish].

This work is available in Open Access model and licensed under a Creative Commons Attribution-NonCommercial 3.0 Poland License - http://creativecommons.org/ licenses/by-nc/3.0/pl/deed.en. 